\title{
The Influence of the Bottom Hole of Cold Extruding Internal Thread on Thread Quality
}

\author{
Hongling HOU*, Xin CHEN*, Yongqiang ZHAO**, Yayin HE**, Changqian WANG** \\ * School of Mechanical Engineering, Shaanxi University of Technology, Hanzhong 723001, China, \\ E-mail:xjtuhhl@163.com;15565520069@163.com \\ **Shaanxi Key Laboratory of Industrial Automation, Shaanxi University of Technology, Hanzhong 723001, China, \\ E-mail:zyq620@163.com;286590438@qq.com; betruemyself@163.com \\ cross ref http://dx.doi.org/10.5755/j02.mech.27435
}

\section{Introduction}

According to statistics, bolt connections account for more than $60 \%$ of the connection methods of modern manufacturing equipment and precision instruments. Therefore, threaded connections directly affect the reliability and service life of equipment operation [1], but bolts on highend equipment in China are almost required $100 \%$ imported. How to improve the reliability and service life of threaded connections is the current research focus of domestic scholars, to meet the strength requirements of threaded connections on high-end mechanical equipment, more and more scholars pay attention to the thread forming process and forming method, they propose to use cold extrusion forming process to improve the fatigue resistance of internal threads, that is, the plastic deformation of the metal is used to fill the thread groove of the extrusion tap with the metal to form the thread profile, in the process of processing, the surface of the internal thread forms a cold work-hardened layer under pressure, which increases the hardness and strength of the metal.

The tooth height rate is a necessary condition to ensure the thread strength, and the tooth height rate of more than $60 \%$ can ensure the thread connection strength. When using the cold extrusion process to process internal threads, the most important factor affecting the tooth height rate is the diameter of the prefabricated bottom hole of the workpiece. Due to the plastic difference of various metals, the diameter of the prefabricated bottom hole of the workpiece is different. MIAO Hong et al. [2-3] conducted internal thread cold extrusion tests on Q460 high-strength steel and analyzed the low-cycle fatigue performance of cold-extruded internal threads. The strengthening mechanism of cold-extrusion internal threads is discussed from the aspects of mechanical properties, surface structure and residual stress. The results show that under low stress cycles, the yield stress of the thread increases and the crack growth rate decreases, and the fatigue life increases with the decrease of the surface grain diameter. And based on genetic algorithm, the process parameters of cold extrusion of internal thread are optimized, which effectively reduces the extrusion torque. Liang Yuxuan et al. [4-5] analyzed the change law of vibration signal during cold extrusion of internal threads with different bottom hole diameters based on vibration tapping technology, explain the influence of the size of the bottom hole diameter on the processing quality of the cold extrusion internal thread from the perspective of the vibration signal, that is, the larger the diameter of the bottom hole, the smaller the amplitude and vibration frequency, and the total energy of the vibration signal decreases; Peter Monka et al. [6] studied the influence of the structural parameters of the tap on the service life of the tap from the perspective of tap failure, and developed a vibration diagnosis system to monitor the stability of the machining process. The results show that the durability of the tool is affected by the helix angle and tapping speed. Yongyi Li [7] et al. optimized the process parameters of internal thread cold extrusion, and determined the optimal value of the bottom hole diameter, extrusion speed and lubricating fluid; Jien-Jong Chen et al. [8-9] studied the load distribution on the thread profile of the bolt and the internal thread based on the finite element method, established an axisymmetric mechanical model and a finite element model, and compared the load distribution of the two models. Guillaume Fromentin [10] studied the geometric characteristics and mechanical properties of cold-extruded internal threads, and the results showed that the surface quality, machining accuracy and load-bearing capacity of extruded internal threads relative to cutting threads are improved. Igor Cézar Pereira et al. [11-14] analyzed the influence of the thread length, the extrusion speed and the diameter of the bottom hole of the workpiece on the thread forming process in extrusion tapping, and determined the position of the maximum torque on the tap during the extrusion process and the best extrusion speed and bottom hole diameter. The above-mentioned documents have conducted different degrees of research on the effect of the bottom hole diameter in the cold extrusion forming process of the internal thread, but there is no targeted study on the relationship between the tooth height rate and the bottom hole diameter. The tooth height rate of the internal thread is closely related to the connection strength, and the bottom hole diameter is a factor that can be controlled in advance during the machining process. The establishment of the relationship between the two is helpful to the smooth implementation of the internal thread cold extrusion process.

This article takes aluminum alloy T6061-T6 and $40 \mathrm{Cr}$ as the research object, and reproduces the extrusion forming process of $\mathrm{M} 8 \times 1.25 \mathrm{~mm}$ internal thread, the internal thread profile of different prefabricated bottom hole diameters was obtained through numerical simulation, and the theoretical formula of bottom hole diameter and tooth height rate was obtained by the polynomial fitting method. The reliability of the formula is verified by experiments, which can be discussed and referenced by experts and scholars in the industry, and it also provides a basis for selecting the diameter of the prefabricated bottom hole for internal thread extrusion. 


\section{The influence of the bottom hole diameter of the work-} piece on the internal thread profile

In the internal thread cold extrusion net forming process, the diameter of the bottom hole of the workpiece is an extremely important parameter, and the amount of metal involved in the plastic deformation is mainly determined by the diameter of the bottom hole. The appropriateness of the bottom hole diameter directly affects the forming effect of the internal thread and determines whether the extrusion process can be successfully completed. As shown in Fig. 1 (in the Fig. $1, H$ is the theoretical tooth height, $h_{a}$ is the actual tooth height), the larger the diameter of the bottom hole, the less metal involved in the extrusion deformation, the lower the tooth height rate, and the lower the thread connection strength; If the diameter of the bottom hole is too small, the metal of the workpiece will fill the thread groove of the extrusion tap during the extrusion process, and the tap will be stuck or even broken. Therefore, in the internal thread cold extrusion process, the optimal value of the diameter of the prefabricated bottom hole of the workpiece must be considered to ensure that the profile height of the internal thread after extrusion is within the specified tolerance range.

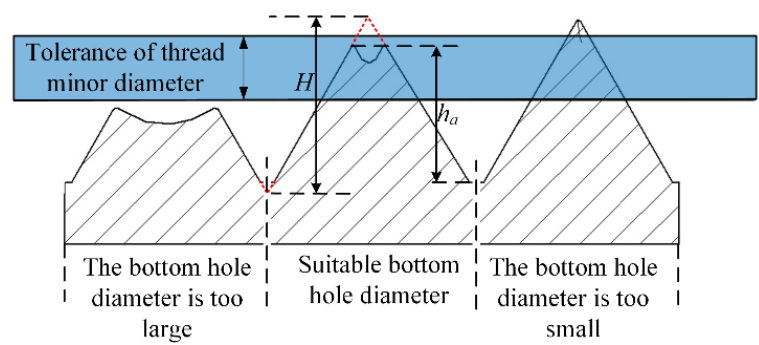

Fig. 1 Influence of base hole diameter on thread profile

The tooth height rate refers to the rate of the actual thread height to the theoretical tooth height. It is the main indicator for judging the saturation of the internal thread. Many literature studies have shown that the relationship between the tooth height rate and the thread strength conforms to the law shown in Fig. 2 [15]. When the tooth height rate is $60 \%$, the thread strength is $95 \%$; when the tooth height rate reaches $80 \%$, the thread strength reaches $100 \%$. Continue to increase the tooth height rate will not increase the thread connection strength, but will lead to a sharp increase in the extrusion torque, Reduce tool life. Therefore, during thread processing, keeping the tooth height rate between $60 \%$ and $80 \%$ not only meets the connection strength but also reduces the difficulty and cost of processing. In the process of threading, it is not easy to directly control the tooth height rate, but the bottom hole diameter can be controlled. As long as the relationship between the tooth height rate and the bottom hole diameter is found, the best bottom hole diameter range can be determined, so as to obtain the connection strength internal thread.

\section{Establishment of finite element model and analysis of numerical simulation results}

\subsection{Establishing the geometric model of extrusion tap}

The traditional extrusion tap is a single-head, that is, the extrusion ridge is ground from a spiral line as the processing track. The single-head extrusion tap has a small lead and a large extrusion torque during processing. In this paper, the geometric model of the double-headed non-standard extrusion tap is established, and the cross-sectional profile curve of the extrusion tap is obtained based on the envelope method, that is, the movement track of the grinding wheel on the thread grinder relative to the extrusion tap blank, as shown in Fig. 3, a. Refer to the design standards for the geometric parameters of the single-head extrusion taps specified in the national standards, and obtain the geometric parameters of the working area of the double-headed six-sided extrusion taps, that is, the extrusion cone angle is $6^{\circ}$, the calibration cone inverted cone angle is $0.085^{\circ}$, and the major diameter of the tap is $d=8 \mathrm{~mm}$, and the amount of shovel back is calculated according to $K=0.02 d$. The established geometric model of the extrusion tap is shown in Fig. 3, b.

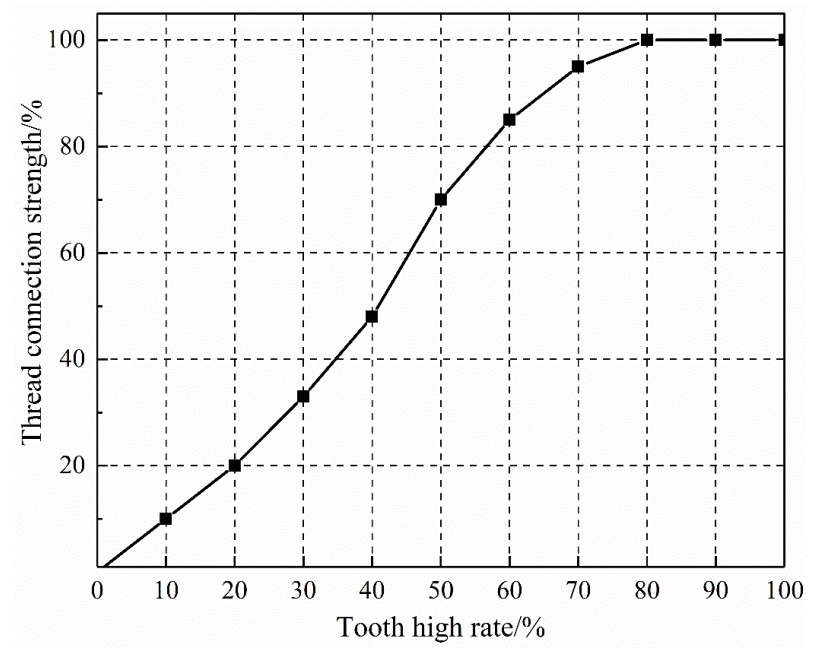

Fig. 2 Relation between tooth height rate and thread connection strength

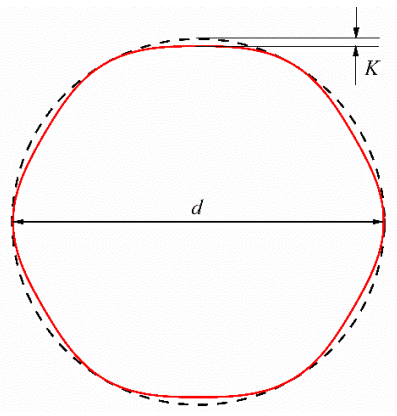

a

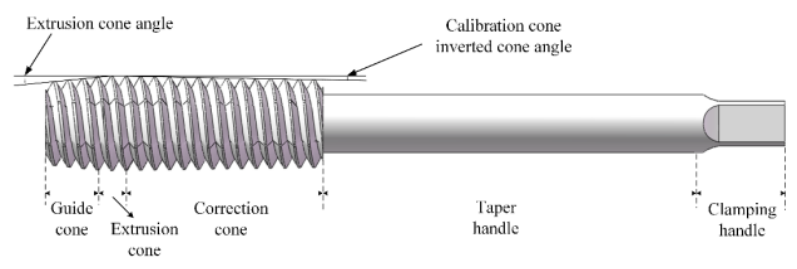

$\mathrm{b}$

Fig. 3 Geometric model of tap: a) Six-sided extrusion tap section profile; b) Extrusion tap structure

\subsection{Establishment of finite element model}

The internal thread extrusion process belongs to the elastoplastic deformation and volume forming process. The finite element solution process involves material nonlinearity, geometric nonlinearity, and contact nonlinearity, which can be solved by rigid-plastic finite element theory. 
Based on the DEFORM-3D software platform to establish the finite element model of the internal thread cold extrusion. The outer contour of the workpiece is a cylinder with a radius of $R=15 \mathrm{~mm}$ and a thickness of $10 \mathrm{~mm}$. The material is set to aluminum alloy T6061-T6 and 40Cr respectively. The flow stress-strain curve is shown in Fig. 4. The workpiece is divided by tetrahedral mesh, and the mesh around the bottom hole is refined to limit the displacement of the workpiece surface in $\mathrm{X}, \mathrm{Y}$, and $\mathrm{Z}$ directions to prevent the workpiece from moving during the simulation process. The extrusion tap is set as a rigid body and will not be deformed during processing. According to the relationship between the lead and the speed, the downward feed speed of the extrusion tap is set to $0.625 \mathrm{~mm} / \mathrm{s}$, the speed is $\pi \mathrm{rad} / \mathrm{s}$, and the friction coefficient is set to 0.08 . The finite element model is shown in Fig. 5.

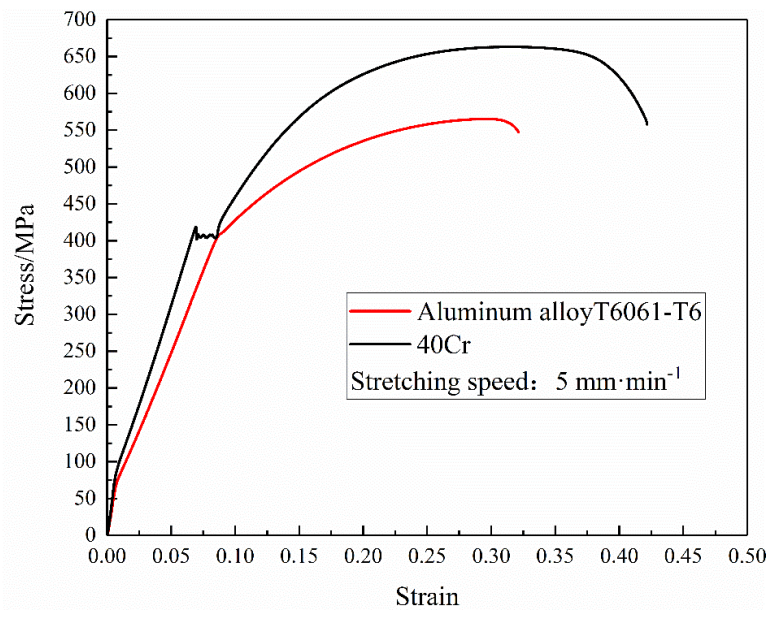

Fig. 4 Stress - Strain curve

M8 $\times 1.25 \mathrm{~mm}$ internal thread has a large diameter of $8 \mathrm{~mm}$ and a pitch of $1.25 \mathrm{~mm}$. Normal tapping in a cutting manner requires a bottom hole with a diameter of $6.8 \mathrm{~mm}$, but extrusion is different from cutting. It uses the plastic flow of metal to fill the thread groove of the extrusion tap and finally forms the thread profile. If the diameter of the bottom hole is too small, the metal will not flow smoothly, the extrusion torque and temperature will rise sharply, which will seriously affect the service life of the extrusion tap, and even cause the extrusion tap to jam or break, increase production costs and reduce processing efficiency. If the diameter of the bottom hole is too large, the internal thread forming will be incomplete, and even the workpiece will be scrapped. In this paper, through a series of simulated extrusion tests, it is finally determined to start with the bottom hole diameter of $7.30 \mathrm{~mm}$ with an interval of $0.03 \mathrm{~mm}$. Establish 6 groups of finite element models with different bottom hole diameters, divide the mesh, and simulate the extrusion process. The detailed parameters of the mesh are shown in Table 1. Take the formed thread profile and extrusion torque as the target to judge the extrusion effect.
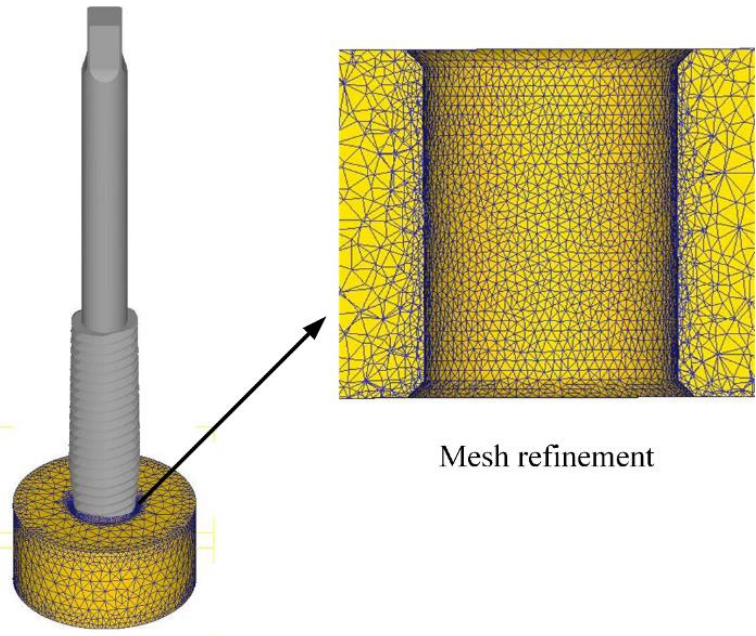

Mesh refinement

Fig. 5 Finite element model of cold extrusion for internal thread

Table 1

Grid details parameters

\begin{tabular}{|c|c|c|c|c|c|}
\hline $\begin{array}{c}\text { Diameter of bottom } \\
\text { hole }\end{array}$ & Number of grids & Size ratio & Number of nodes & Number of elements & Number of surface polyhedrons \\
\hline $7.30 \mathrm{~mm}$ & 100000 & 4 & 21947 & 111166 & 12436 \\
\hline $7.33 \mathrm{~mm}$ & 100000 & 4 & 20253 & 100985 & 12434 \\
\hline $7.36 \mathrm{~mm}$ & 100000 & 4 & 20238 & 100895 & 12444 \\
\hline $7.39 \mathrm{~mm}$ & 100000 & 4 & 20219 & 100730 & 12440 \\
\hline $7.42 \mathrm{~mm}$ & 100000 & 4 & 21839 & 110440 & 12452 \\
\hline $7.45 \mathrm{~mm}$ & 100000 & 4 & 22519 & 114402 & 12484 \\
\hline
\end{tabular}

\subsection{Numerical simulation analysis}

The cold extrusion of the internal thread starts, the guide cone first contacts the inner wall of the bottom hole, and the thread marks are extruded on the inner wall of the workpiece. With the downward feeding of the extrusion cone, the depth of the extrusion ridge cut into the workpiece gradually increases, and the amount of metal involved in the deformation of the workpiece increases, forming an internal thread profile. The extrusion tap continues to feed, and the correction cone corrects the internal thread profile to gradually form a complete and full internal thread. After the internal thread is corrected by 4 to 5 corrective tapered teeth, the internal thread is completely formed, forming a clearer thread profile. The complete extrusion process is shown in Fig. 6.
The changing trend of the torque carried by the tap during the extrusion process is shown in Fig. 7. When the guide cone is introduced into the bottom hole of the workpiece, the extrusion torque rises sharply. When the guide cones all enter the bottom hole of the workpiece, the extrusion cone starts to work. As the extrusion cone deepens, the contact area between the tap and the workpiece increases, and the extrusion torque rises slightly. After the extrusion cone completely enters the bottom hole of the workpiece, the correction cone part starts to work. Due to the inverted cone angle, the contact area between the tap and the workpiece gradually decreases, and the extrusion torque begins to decrease until the extrusion is completed, and the extrusion torque drops to zero. 


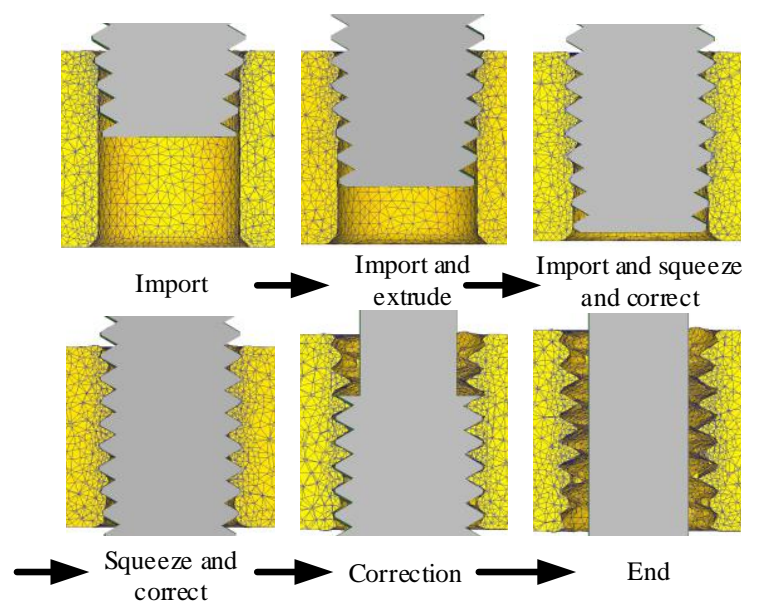

Fig. 6 Numerical simulation of cold extrusion for internal thread

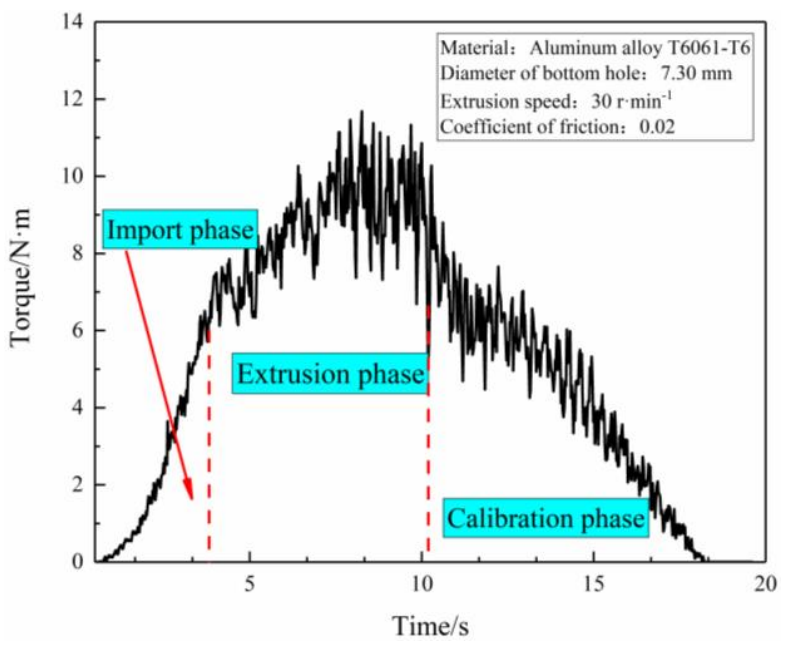

Fig. 7 Torque variation during extrusion

\subsection{Simulation results}

After the extrusion, the tooth shape extrusion effect with different bottom hole diameters is obtained as shown in Fig. 8. It can be clearly seen from the Fig. 8 that when the diameter of the bottom hole is $7.30 \sim 7.33 \mathrm{~mm}$, the tooth shape is relatively complete, the outline is clear, and the extrusion effect is better; When the diameter of the bottom hole gradually increased to $7.45 \mathrm{~mm}$, the extruded internal thread profile was incomplete, the crest was missing, the tooth height rate was significantly reduced to less than half, and the extrusion effect was poor.

To establish the relationship between the extrusion effect and the diameter of the bottom hole, the tooth height of the simulated internal thread was measured, and the corresponding tooth height rates for different bottom hole diameters were calculated as shown in Table 2.
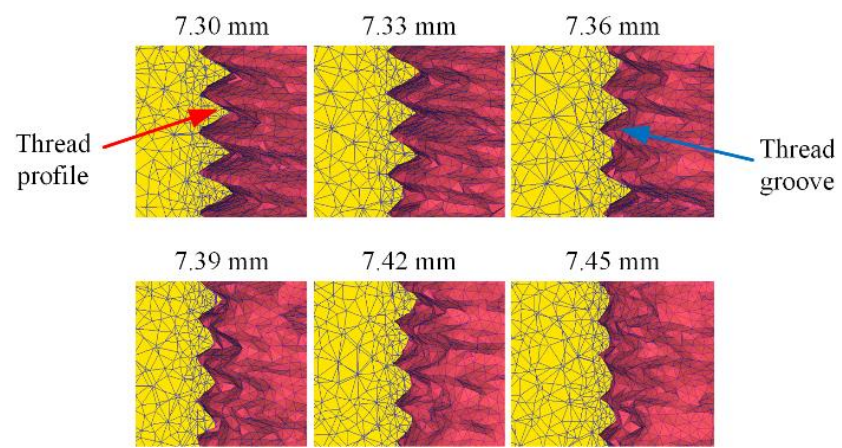

$7.42 \mathrm{~mm}$

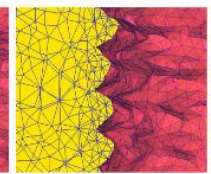

$7.45 \mathrm{~mm}$

a

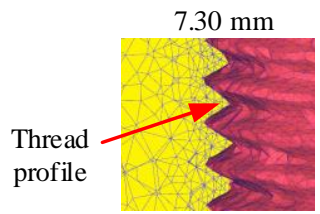

$7.33 \mathrm{~mm}$

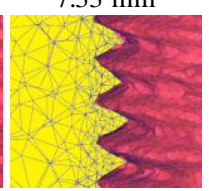

$7.36 \mathrm{~mm}$
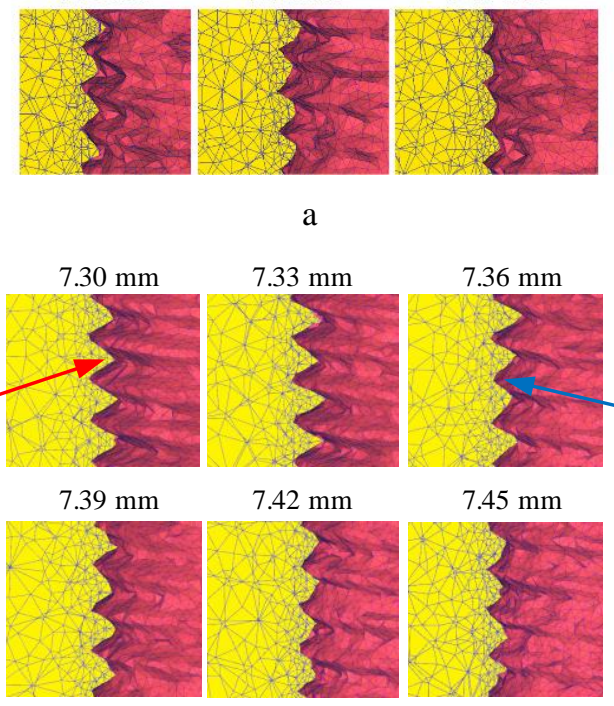

b

Fig. 8 Simulation results of internal thread profile: a) Aluminum alloy T6061-T6; b) 40Cr

Table 2

Simulation results of bottom hole diameter and tooth height rate

\begin{tabular}{|c|c|c|c|c|c|c|}
\hline Diameter of bottom hole $x, \mathrm{~mm}$ & 7.3 & 7.33 & 7.36 & 7.39 & 7.42 & 7.45 \\
\hline Aluminum alloy T6061-T6 's tooth height rate $y_{1}$ & $91.45 \%$ & $84.99 \%$ & $79.45 \%$ & $67.44 \%$ & $51.73 \%$ & $37.88 \%$ \\
\hline 40Cr 's tooth height rate $y_{2}$ & $84.8 \%$ & $80.3 \%$ & $74.1 \%$ & $66.9 \%$ & $49.6 \%$ & $44.2 \%$ \\
\hline
\end{tabular}

\subsection{Test data processing}

Polynomial fitting to discrete points has been proven to be an effective method of experimental data processing [16]. According to Taylor's theorem, any continuous function can be decomposed into a polynomial as in equation (1). In curve fitting, a nonlinear function is often converted into a linear polynomial for fitting. This paper proposes a polynomial method to fit the above-mentioned experimental data, that is:

$$
y=f(x)=\sum_{n=0}^{N} a_{n} x_{n} .
$$

The order of the fitting polynomial can be selected according to the characteristics of the actual experimental data. As the order increases, the fitting curve will become unsmooth. During the fitting, the data were fitted according to the 2,3 , and 4 orders respectively. After considering the fitting accuracy, the result of the cubic polynomial fitting was selected as the final result. After fitting in MATLAB, the cubic polynomial function between the bottom hole diameter and the tooth height rate of the two materials is shown in Eqs. (2) and (3).

$$
\begin{aligned}
& y_{1}=-1.87243 \times 10^{3} \times x^{3}+4.00093 \times 10^{4} \times x^{2}- \\
& -2.84966 \times 10^{5} \times x+6.76654 \times 10^{5} . \\
& y_{2}=1.17284 \times 10^{4} \times x^{3}-2.60217 \times 10^{5} \times x^{2}+ \\
& +1.92412 \times 10^{6} \times x-4.7415958 \times 10^{6} .
\end{aligned}
$$


After the data is fitted, the mean square error MSE is used to measure the polynomial fitting result, according to formula (4):

$$
M S E=\sum_{i=1}^{n} \frac{1}{n}\left(f\left(x_{i}\right)-y_{i}\right)^{2} .
$$

The mean square error MSE of the above $\mathrm{y}_{1}$ and $\mathrm{y}_{2}$ fitting curves are 3.46 and 1.568. The smaller the value of $M S E$, it indicates that the prediction model has better accuracy in describing the experimental data, the prediction model after data fitting in this paper can accurately reflect the relationship between the bottom hole diameter and the tooth height rate.

Fig. 9 shows the tooth height rate curve after MATLAB fitting. Comprehensive analysis of the conclusion of Fig. 2 shows that when the diameter of the bottom hole of the workpiece is $7.30 \mathrm{~mm}$, the tooth height rate of the internal thread of the two materials is more than $85 \%$, and the thread connection strength is $100 \%$; When the diameter of the bottom hole is expanded to $7.42 \mathrm{~mm}$, the tooth height rate is less than $60 \%$, and the thread strength drops to less than $90 \%$, which will cause hidden dangers to the reliability and service life of the equipment. According to the conclusion of the aforementioned literature, when the tooth height rate is $60 \%$ to $80 \%$, the connection strength can be guaranteed and the extrusion can be smooth. Therefore, on the fitting curve, find out that the diameter of the bottom hole corresponding to the two positions of $60 \%$ and $80 \%$ is between $7.3 \mathrm{~mm}-7.4 \mathrm{~mm}$, which is the ideal bottom hole diameter range. In the actual extrusion of internal threads, the prefabricated holes can be made in this range, and then the profile size of the extrusion profile can be further improved by optimizing the process parameters.

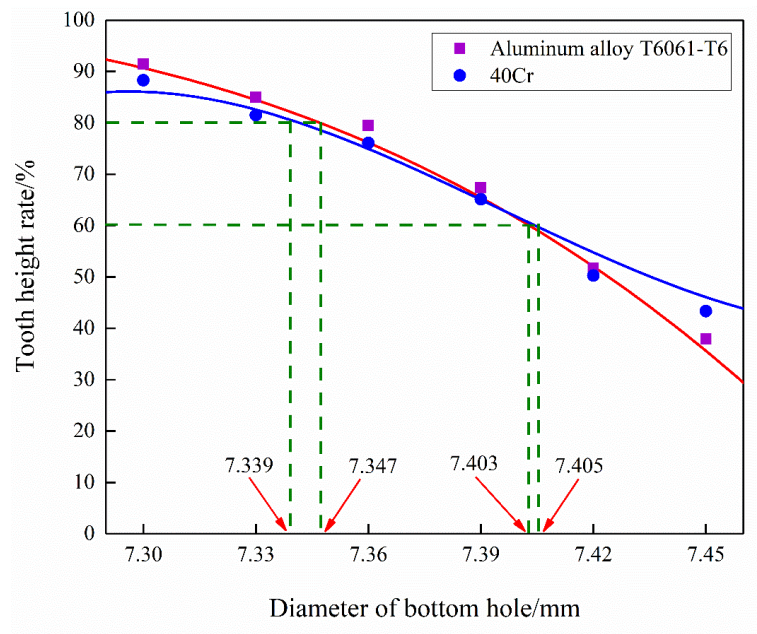

Fig. 9 Simulated tooth height rate fitting curve

\section{Extrusion test research}

\subsection{Specimen preparation}

A test piece with a thickness of $10 \mathrm{~mm}$ was cut from a 30mm diameter aluminum alloy T6061-T6 and 40Cr bar. Using a combination of standard twist drills and special reamer fine reaming, 12 test pieces with different bottom hole diameters of 7.30 7.45 $\mathrm{mm}$ were prepared, as shown in Fig. 10, a. The above-mentioned non-standard double- end cylindrical arrangement six-sided extrusion taps are processed on a thread grinder as shown in Fig. 10b.

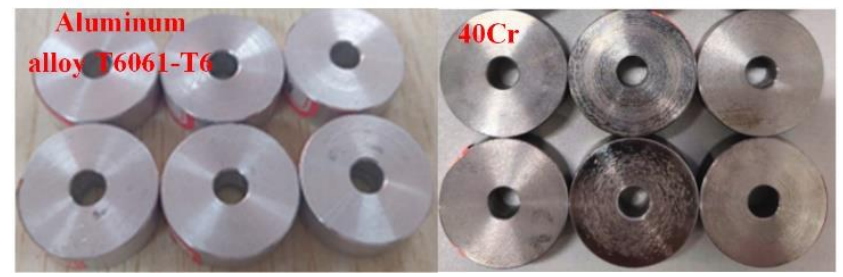

a

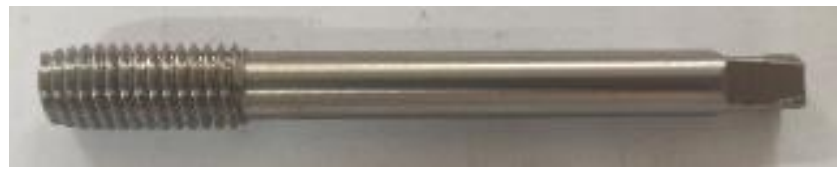

b

Fig. 10 Test preparation: a) The specimen; b) Doubleheaded cylindrical extruding taps with six edges

\subsection{Test and results}

Use a certain domestic tapping machine for tapping. After each test piece was tapped, it was cut along the axis on a Posittec wire cutting machine to obtain the axial cross-sections of the extruded internal threads of the two materials. Use $10 \%$ dilute hydrochloric acid to remove surface impurities, and use the JVC-300T automatic video measuring instrument to zoom in. You can see that the thread profile is full and the pitch is uniform, indicating a good finish. The cross-sectional shape of the two threads is shown in Fig. 11.
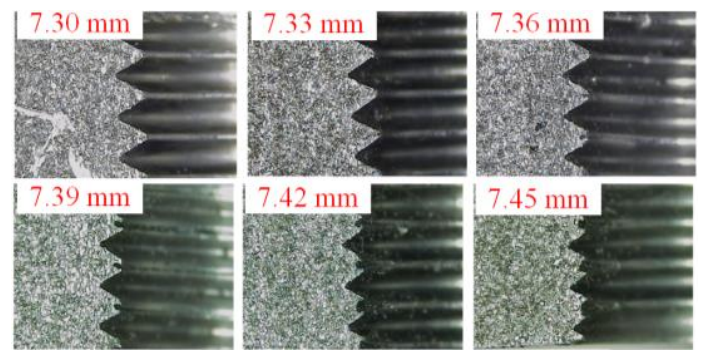

a
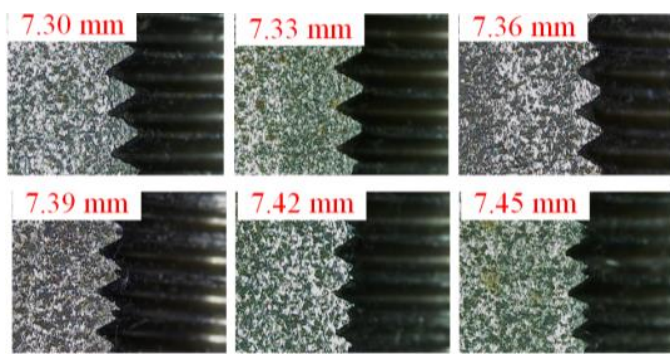

b

Fig. 11 Test results. a) Aluminum alloy T6061-T6; b) 40Cr

From Fig. 11, it can be seen that when the diameter of the bottom hole is $7.30 \mathrm{~mm}$, the internal thread profile is very full. As the bottom hole expands to $7.39 \mathrm{~mm}$, it can be seen that there is a tiny U-shaped gap at the top of the tooth. When the diameter of the prefabricated bottom hole is enlarged to more than $7.42 \mathrm{~mm}$, the crest of the internal thread has a larger gap. The test results are basically consistent with the conclusions obtained by the previous numerical simulations. 


\subsection{Comparison of fitted curves}

In order to verify whether the fitting relationship of the tooth height rate obtained above is reliable, the tooth height rate result obtained by the experiment is compared with this. Measure the tooth height of each extruded specimen and calculate the corresponding tooth height rate. The comparative analysis of test data and simulation data is shown in Table 3 . The relationship between tooth height rate and the bottom hole diameter is shown in Fig. 12. In the Fig. 12, when the tooth height rate is $60 \%-80 \%$, the diameter of the bottom hole corresponds to the diameter range. It can be seen that the diameter ranges of aluminum alloy T6061-T6 and 40Cr obtained through the experiment is between $7.336 \mathrm{~mm}-7.396 \mathrm{~mm}$ and $7.339 \mathrm{~mm}-7.405 \mathrm{~mm}$, and the diameter obtained by simulation is between 7.347$7.403 \mathrm{~mm}$ and $7.336 \mathrm{~mm}-7.40 \mathrm{~mm}$. The errors of aluminum alloy T6061-T6 and 40Cr are within $0.007 \mathrm{~mm} 0.011 \mathrm{~mm}$ and $0.003 \mathrm{~mm} \sim 0.005 \mathrm{~mm}$, respectively.

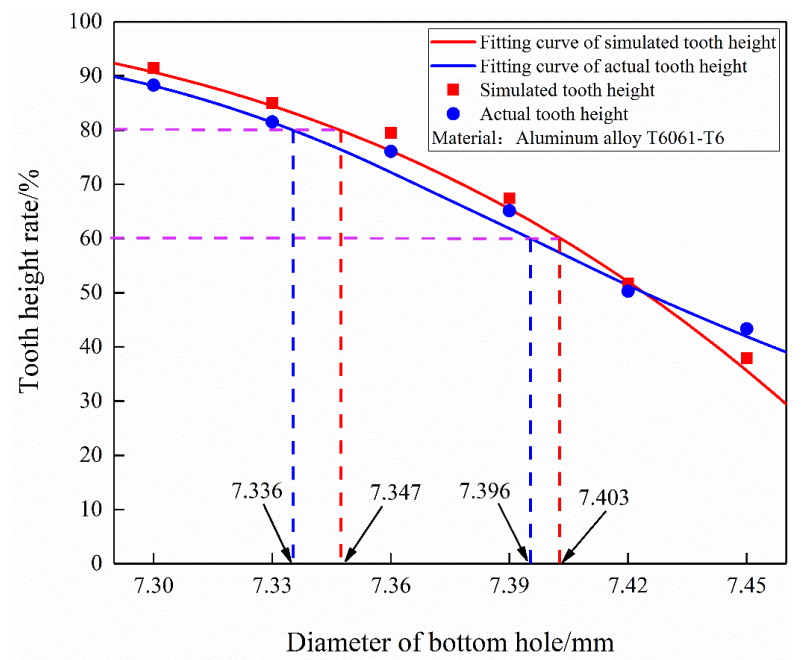

a
In Fig. 12, when the diameter of the bottom hole is $7.30 \mathrm{~mm}$, the actual tooth height rate of aluminum alloy T6061-T6 and 40Cr measured by the test reaches $88.31 \%$ and $84.8 \%$. With the expansion of the bottom hole to 7.39 $\mathrm{mm}$, the actual tooth height rate decreased to $65.13 \%$ and $66.9 \%$. When the diameter of the bottom hole is enlarged to $7.42 \mathrm{~mm}$, the actual tooth height rate of aluminum alloy T6061-T6 and 40Cr are both lower than $60 \%$. It can be seen that the numerical simulation results of the tooth height rate are consistent with the test results, indicating that the relationship between the bottom hole diameter and the tooth height rate obtained by the numerical simulation is correct and reliable, and can be used to guide actual processing. At the same time, it is proved that numerical simulation can be used to replace part of the tests when the internal thread is extruded, which provides a method and basis for the subsequent work.

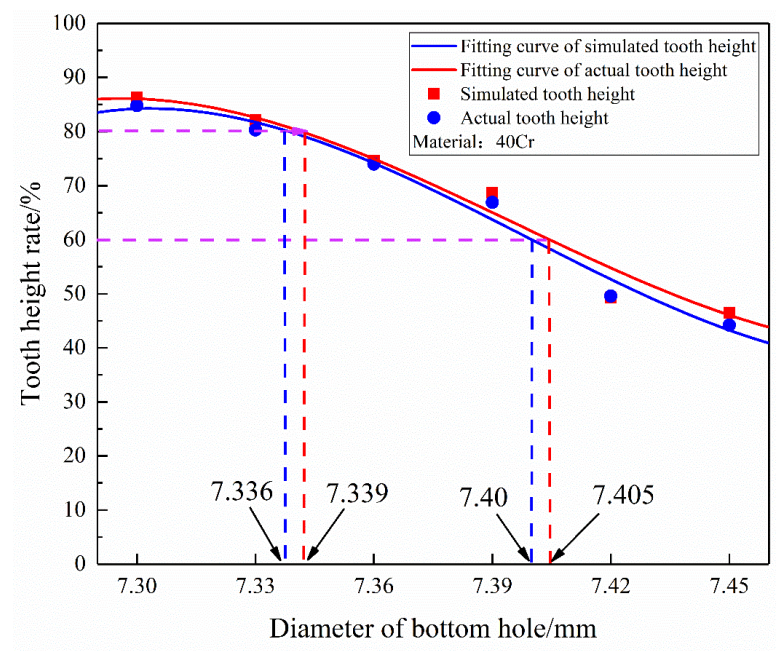

b

Fig. 12 Comparison of simulated and experimental dental rates: a) Aluminum alloy T6061-T6; b) 40Cr

Table 3

Statistical results of bottom hole diameter and tooth height rate

\begin{tabular}{|c|c|c|c|c|c|c|c|}
\hline \multicolumn{2}{|c|}{ Diameter of bottom hole: mm } & 7.3 & 7.33 & 7.36 & 7.39 & 7.42 & 7.45 \\
\hline \multirow{2}{*}{ Simulated tooth height rate } & Aluminum alloy T6061-T6 & $91.45 \%$ & $84.99 \%$ & $79.45 \%$ & $67.44 \%$ & $51.73 \%$ & $37.88 \%$ \\
\cline { 2 - 8 } & $40 \mathrm{Cr}$ & $86.3 \%$ & $82.1 \%$ & $74.6 \%$ & $68.7 \%$ & $49.3 \%$ & $46.5 \%$ \\
\hline \multirow{2}{*}{ Test tooth high rate } & Aluminum alloy T6061-T6 & $88.31 \%$ & $81.52 \%$ & $76.09 \%$ & $65.13 \%$ & $50.27 \%$ & $43.34 \%$ \\
\cline { 2 - 8 } & $40 \mathrm{Cr}$ & $84.8 \%$ & $80.3 \%$ & $74.1 \%$ & $66.9 \%$ & $49.6 \%$ & $44.2 \%$ \\
\hline
\end{tabular}

\section{Conclusion}

Aiming at the problem that the diameter of the prefabricated bottom hole of the workpiece is difficult to determine in the internal thread cold extrusion process, a method for constructing the relationship between the diameter of the prefabricated bottom hole of the workpiece and the tooth height rate based on polynomial fitting is proposed. The theoretical formula for calculating the diameter of the bottom hole and the tooth height rate is obtained. As long as the diameter of the bottom hole is selected appropriately, the extruded thread profile can reach a certain height to ensure reliable connection.

\section{Acknowledgements}

This project was funded by the Shaanxi Provincial
Natural Science Basic Research Project (2019JM-466), the Shaanxi Provincial Department of Education Special Scientific Research Project (18JK0148), and the Shaanxi University of Technology Graduate Innovation Fund Project (SLGYCX2027).

\section{References}

1. Wang, M. 1998. Principle and technology of anti-fatigue manufacturing, Jiangsu Science and Technology Press.

https://xueshu.baidu.com/usercenter/paper/show?paperid $=744 \mathrm{cdc} 225694 \mathrm{c} 13 \mathrm{eb} 2509 \mathrm{ab} 29 \mathrm{ece} 6 \mathrm{e} 70 \&$ site $=$ xue shu_se\&hitarticle $=1 \&$ sc_from=snut.

2. Miao, H.; Mei, Q.; Yuan, J. Y.; et al. 2016. Low cycle fatigue and strengthening mechanism of cold extruded 
large diameter internal thread of Q460 steel, Chinese Journal of Mechanical Engineering, p. 556-563. http://dx.doi.org/10.3901/CJME.2016.0318.033.

3. Miao, H.; Zuo, D. W.; Wang, H. J.; et al. 2010. Optimization of tap parameters for internal thread cold extrusion of high strength steel based on genetic algorithm, Key Engineering Materials p. 431-432, 434-437.

http://dx.doi.org/10.4028/www.scientific.net/KEM.431-432.434.

4. Liang, Y. X.; Li, X. F.; Zuo, D. W.; et al. 2012.Effect of bottom hole diameter on vibration signal of internal thread in cold extrusion, Precision forming engineering 4(02):10-14+35.

http://dx.doi.org/10.3969/j.issn.16746457.2012.02.003.

5. Zhang, M. 2011.Research on quality Prediction of cold extrusion Internal thread forming based on multi-sensor information fusion, Nanjing University of Aeronautics and Astronautics. http://dx.doi.org/10.7666/d.d178374.

6. Monka, P.; Monkova, K.; Modrak, V.; et al. 2019. Study of a tap failure at the internal threads machining, Engineering Failure Analysis 100: 25-36. http://dx.doi.org/10.1016/j.engailanal.2019.02.035.

7. Li, Y. Y. ; Zhao, S. D . 2011. Numerical analysis on the key technology in extrusion tapping of internal thread, Advanced Materials Research 341-342: 436-441.

http://dx.doi.org/10.4028/www.scientific.net/AMR.341-342.436.

8. Chen, J. J.; Shih, Y. S. 1999. A study of the helical effect on the thread connection by three dimensional finite element analysis, North-Holland 191(2). http://dx.doi.org/10.1016/S0029-5493(99)00134-X.

9. Lee, B. Y. ; Tarng, Y. S. ; Lii, H. R. . 2000. An investigation of modeling of the machining database in turning operations, Journal of Materials Processing Technology 105(1-2): 1-6. http://dx.doi.org/10.1016/S0924-0136(00)00535-5.

10. Fromentin, G. ; Gérard, P.; Moisan, A. et al. 2005. Precision and surface integrity of threads obtained by form tapping, CIRP Annals - Manufacturing Technology 54(1): 519-522. http://dx.doi.org/10.1016/S0007-8506(07)60159-0.

11. Pierre, Stéphan.; Mathurin, F.; Guillot, J. 2011. Analytical study of maximal tapping torque during forming screw process, Journal of Materials Processing Technology $211(2): 212-221$.

http://dx.doi.org/10.1016/j.jmatprotec.2010.09.013.

12.Z, Yang.; Q,Tan.; E, Shiju. 2004.On-line monitoring of drilling torques of microdrills, Proceedings of the Institution of Mechanical Engineers Part B Journal of Engineering Manufacture 218: 1735-1740. http://dx.doi.org/10.1177/095440540421801208.

13. Pereira; Igor, Cézar.; Da, Silva. M. B . 2017. Study of the internal thread process with cut and form taps according to secondary characteristics of the process, International Journal of Advanced Manufacturing Technology 93(5-8), 2357-2368.

http://dx.doi.org/10.1007/s00170-017-0573-x.
14. Armarego, E. J. A. ; Chen, M. N. P . 2002. Predictive Cutting Models for the Forces and Torque in Machine Tapping with Straight Flute Taps, Cirp Annals 51(1): 75-78. http://dx.doi.org/10.1016/S0007-8506(07)61469-3.

15. Huang, X. L.; Li, X. F.; Zuo. D. W. et al. 2012. Optimization of internal thread cold extrusion process parameters based on numerical simulation, Forging technology (06): 193-198.

http://dx.doi.org/10.3969/j.issn.10003940.2012.06.046.

16. Zhang, Y. J.; Zhang, J. W. 2012. Design of automatic resistance Tester and its Error treatment, Electronic measurement technology 35 (3): 87-89. http://dx.doi.org/10.3969/j.issn.10027300.2012.03.022.

H. Hou, X. Chen, Y. Zhao, Y. He, Ch. Wang

\section{THE INFLUENCE OF THE BOTTOM HOLE OF COLD EXTRUDING INTERNAL THREAD ON THREAD QUALITY}

S u m m a r y

The diameter of the threaded bottom hole determines whether the extrusion can proceed smoothly and the fullness of the tooth shape after extrusion. The tooth height rate is an important indicator of the strength of the threaded connection. In order to establish the relationship between the diameter of the bottom hole and the tooth height rate of the extruded internal thread, this article takes the aluminum alloy T6061-T6 and 40Cr internal thread with a size of $\mathrm{M} 8 \times 1.25 \mathrm{~mm}$ as an example, and uses a method of combining numerical simulation and process test. Obtained the change law of internal thread profile and tooth height rate after extrusion of workpieces with different bottom hole diameters of two materials. Using MATLAB to fit the numerical simulation results of the two materials, the relationship between the internal thread tooth height rate and the diameter of the prefabricated bottom hole of the workpiece was obtained. The reliability of the numerical simulation results and the feasibility of the fitting formula are verified through experiments. The results show that the diameter of the prefabricated bottom hole of the workpiece is controlled within $7.33 \sim 7.39 \mathrm{~mm}$ when the $\mathrm{M} 8 \times 1.25 \mathrm{~mm}$ internal thread is processed by the cold extrusion process. The high rate of the internal thread after extrusion meets the requirements of thread connection strength, and the internal thread has high forming quality and good surface quality.

Keywords: cold extrusion internal thread, diameter of bottom hole, quality of internal thread, numerical simulation, experimental verification.

Received August 02, 2020 Accepted August 07, 2021 